\title{
Моделирование реакции сверхвысокочастотного низкобарьерного неохлаждаемого диода Мотта на воздействие тяжелых заряженных частиц космического пространства и фемтосекундных лазерных импульсов
}

\author{
(C) А.С. Пузанов ${ }^{1,2}$, В.В. Бибикова ${ }^{1,2}$, И.Ю. Забавичев ${ }^{1,2}$, Е.С. Оболенская ${ }^{1}$, А.А. Потехин ${ }^{2}$, \\ Е.А. Тарасова ${ }^{1}$, Н.В. Востоков ${ }^{3}$, В.А. Козлов ${ }^{3}$, С.В. Оболенский ${ }^{1,2}$ \\ ${ }^{1}$ Нижегородский государственный университет им. Н.И. Лобачевского, \\ 603950 Нижний Новгород, Россия \\ ${ }^{2}$ Филиал РФЯЦ-ВНИИЭФ „НИИИС им. Ю.Е. Седакова“, \\ 603950 Нижний Новгород, Россия \\ ${ }^{3}$ Институт фризики микроструктур Российской академии наук, \\ 603950 Нижний Новгород, Россия \\ E-mail: puzanov@rf.unn.ru
}

Поступила в Редакцию 12 апреля 2021 г.

В окончательной редакции 19 апреля 2021 г.

Принята к публикации 19 апреля 2021 г.

\begin{abstract}
Проведен теоретический анализ деградации вольт-амперной характеристики и переходных ионизационных процессов, протекающих в низкобарьерном неохлаждаемом GaAs-диоде Мотта при воздействии тяжелых заряженных частиц космического пространства и имитирующих их импульсов лазерного излучения. Реакция диода на воздействие ионов мышьяка с энергией $200 \mathrm{MэB,} \mathrm{соответствующей} \mathrm{линейной} \mathrm{передаче}$ энергии $26 \mathrm{MэB} \cdot \mathrm{cm}^{2} / \mathrm{Mг}$, сопоставляется с откликом на воздействие фемтосекундных импульсов оптического излучения длительностью 10 фс с длинами волн 870 и 670 нм.
\end{abstract}

Ключевые слова: диод Мотта, тяжелые заряженные частицы, фемтосекундный лазерный импульс.

DOI: 10.21883/FTP.2021.09.51288.17

\section{1. Введение}

Развитие перспективных систем для обеспечения быстродействующей связи, в том числе космического базирования [1], требует разработки приемников и передатчиков сантиметрового, а в будущем миллиметрового диапазонов длин волн, стойких к воздействию ионизирующих излучений космического пространства. Одним из полупроводниковых приборов для сверхвысокочастотной аппаратуры является неохлаждаемый GaAsдиод Мотта с пониженной эффективной высотой потенциального барьера на границе металл-полупроводник. Понижение эффективной высоты барьера достигается за счет изотипного $\delta$-легирования полупроводникового $i$-слоя на расстоянии нескольких нанометров от металла [2]. В результате в полупроводнике формируется потенциальный рельеф с туннельно-прозрачным барьером на границе с металлом, что уменьшает эффективную высоту барьера диода до значений, позволяющих не использовать постоянное смещение при детектировании. Это упрощает конструкцию приемника и приводит к снижению уровня шумов из-за отсутствия постоянного тока смещения. В смесительном режиме работы снижение эффективной высоты барьера позволяет уменьшить необходимый уровень мощности гетеродина [3], в выпрямительном режиме - увеличивает эффективность преобразования RF-DC при низких уровнях мощности микроволнового сигнала [4]. Низкобарьерные GaAs-диоды Мотта использовались в качестве нелинейных элемен- тов при решении различных задач и показали высокую эффективность при детектировании [5-8], смешении [3,9] и выпрямлении [10] сигналов коротковолновой части миллиметрового диапазона длин волн.

Отсутствие диэлектрических слоев в рабочей области диода предполагает его высокую стойкость к постепенной деградации характеристик за счет накопления зарядов при воздействии электронного и протонного излучений космического пространства. Однако малые геометрические размеры элемента (с целью достижения высокочастотных свойств) могут обеспечить высокую чувствительность к переходным ионизационным процессам, протекающим в полупроводниковых структурах при воздействии тяжелых заряженных частиц космического пространства, в том числе первичных атомов отдачи, возникающих из-за рассеяния протонов на атомах вещества.

Существующие методы испытаний с использованием ускорителей характеризуются высокой стоимостью, трудоемкостью и сеансовым режимом работы [11]. Поэтому интерес представляет развитие имитационных методов оценки реакции изделий микро- и наноэлектроники на воздействие тяжелых заряженных частиц космического пространства при помощи пикосекундных (1-600 пс) и фемтосекундных $(10-1000$ фс) лазеров оптического диапазона [12].

Физическая обоснованность имитации воздействия тяжелых заряженных частиц лазерным излучением пикосекундной длительности заключается в способности 
генерации в локальном объеме полупроводника неравновесных носителей заряда. При этом, несмотря на то что при воздействии лазерного излучения и при пролете иона пространственно-временны́е профили распределения неравновесных носителей заряда существенно различаются, в большинстве полупроводниковых приборов за счет процессов амбиполярной диффузии к началу формирования электрической реакции низкочастотных структур (через времена $\sim 100$ пс) различия в структуре ионизации практически исчезают. Эти условия, однако, не выполняются для высокочастотных структур, важную роль в которых играют „горячие“ носители заряда, а электрическая реакция формируется в течение нескольких пикосекунд после воздействия тяжелой заряженной частицы космического пространства. К настоящему времени не рассмотрен вопрос адекватности подобной замены для исследований и испытаний нанометровых полупроводниковых приборов, когда воздействие тяжелых заряженных частиц приводит к генерации горячих носителей заряда [13], которые при их движении к контактам прибора не успевают остыть. Из-за того что скорость таких электронов и дырок будет существенно отличаться от скорости термализованных носителей, форма импульса тока станет зависимой от длины активной области полупроводникового прибора, а также от направления движения тяжелой заряженной частицы. В данной работе проведено сравнение действия тяжелой заряженной частицы и фемтосекундного лазерного импульса различной энергии квантов на диод Мотта с длиной активной области 100 нм.

\section{2. Объект моделирования}

В качестве объекта моделирования была выбрана структура $\mathrm{Al} / \mathrm{GaAs}$ низкобарьерного диода из работы [14]: толщина слабо легированного $i$-слоя (активная область диода) составляла 100 нм, концентрация примеси в активной области $-1.0 \cdot 10^{14} \mathrm{~cm}^{-3}$, концентрация примеси в подложке - 5.0 $10^{17} \mathrm{~cm}^{-3}$, слоевая концентрация доноров в $\delta$-слое $-8.8 \cdot 10^{12} \mathrm{~cm}^{-2}$, расстояние от $\delta$-слоя до границы с металлом равнялось 4.7 нм. При проведении расчетов предполагалось, что площадь барьерного контакта диода равна 1 мкм $^{2}$, а сам контакт идеальный, т. е. не влияет на процесс генерации электроннодырочных пар в полупроводнике. Время жизни неравновесных носителей заряда задавалось равным 10 нс [15], что существенно больше длительности возбуждающего воздействия.

\section{3. Математическая модель}

Для моделирования воздействия тяжелых заряженных частиц и лазерного излучения на диод Мотта использовалась разработанная ранее модель на основе метода Монте-Карло [16], а также оригинальная локальнонеравновесная модель переноса носителей заряда [17], в которую для учета горячих радиационно-генерированных неравновесных носителей заряда были добавлены уравнения баланса энергии и импульса электронов и дырок. Последняя калибровалась по расчетам методом Монте-Карло и использовалась для проведения расчетов формы импульсов тока, генерируемых при облучении диодов тяжелыми заряженными частицами и лазерным излучением. С помощью метода Монте-Карло учитывался спектр горячих радиационно-генерированных неравновесных носителей заряда в треке заряженной частицы $[18,19]$, а также анализировались особенности изменения энергии и скорости электронов при их движении в активной области диода Мотта.

\section{4. Результаты и их обсуждение}

Действие корпускулярных излучений на полупроводники приводит к уменьшению концентрации основных носителей заряда и снижению их подвижности, а также уменьшению времени жизни неосновных носителей заряда. Теоретический анализ показывает, что деградация статической вольт-амперной характеристики $j(U)$ диода Мотта при воздействии протонов космического

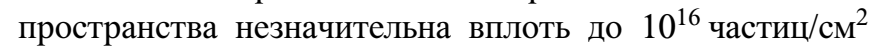
(рис. 1).

При воздействии тяжелой заряженной частицы характерный диаметр ионизованной области вокруг трека иона составляет $\sim 10 \mathrm{Hм}$ [20]. Фокусировка лазерного излучения в область такого размера практически невозможна, характерный диаметр пятна излучения составляет 1-2 мкм [12]. Поэтому, учитывая площадь диода, рассматривали равномерную ионизацию активной области диода и последующий сбор носителей контактами.

Количество неравновесных носителей заряда в полупроводниковой структуре и, следовательно, амплитуда импульса тока определяются величинами линейной передачи энергии тяжелой заряженной частицы и длиной

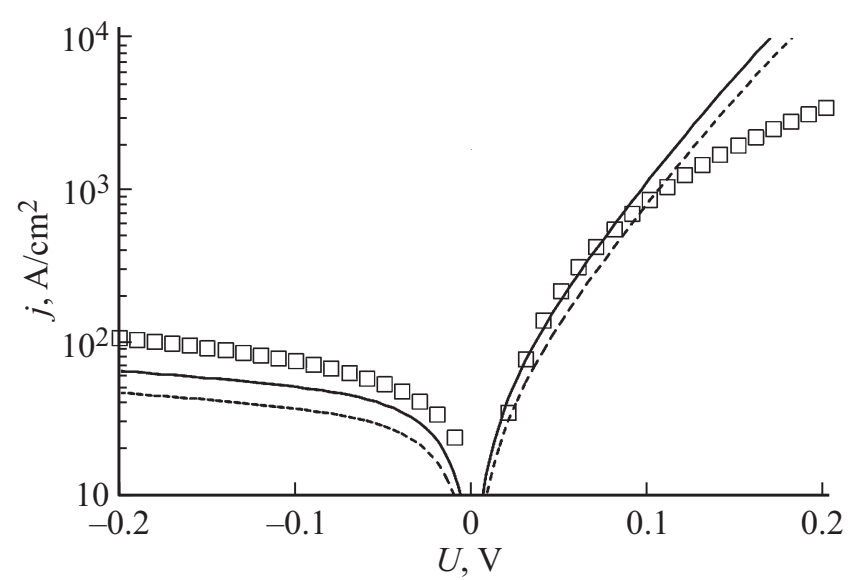

Рис. 1. Статическая вольт-амперная характеристика диода Мотта: точки - эксперимент [14], сплошная линия - расчет до облучения, штриховая линия - расчет после протонного

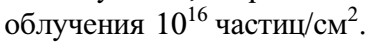


трека иона в рабочей области диода. Рассматривалось прохождение иона As c энергией 200 МэВ и линейной передачей энергии $26 \mathrm{MэB} \cdot \mathrm{cm}^{2} /$ мг. При помощи программы SRIM [21] можно показать, что эта величина является максимальной, т. е. реализуется наихудший случай при рассеянии протонов на атомах Ga и As. B ходе вычислительного эксперимента рассматривались варианты прохождения тяжелой заряженной частицы через рабочую область перпендикулярно оси анод-катод: в слабо легированной $i$-области, в сильно легированной n-области. Варьировались разогрев электронно-дырочного газа лазерным излучением путем изменения его длины волны и область прохождения заряженной частицы через структуру диода. В качестве источника оптического излучения в работе рассматривался титансапфировый лазер с перестраиваемой длиной волны. Моделировалось воздействие лазерного импульса с длинами волны $870 \mathrm{Hм}$, что соответствует энергии фотонов 1.43 эВ, и $670 \mathrm{Hм}$, что дает энергию фотонов 1.85 эВ. В первом случае энергия фотонов равна ширине запрещенной зоны GaAs, что приводит к возникновению изначально термализованных электронно-дырочных пар. Во втором случае энергия фотонов больше ширины запрещенной зоны, поэтому генерируются горячие электроны и дырки. Максимальная интенсивность лазерного излучения подбиралась таким образом, чтобы величина собранного заряда, т.е. интеграл от полного тока, была идентичной величине в случае воздействия тяжелых заряженных частиц.

\section{1. Трек заряженной частицы перпендикулярен линиям тока в $\boldsymbol{i}$-области}

При попадании тяжелой заряженной частицы в область $i$-слоя реализуется квазибаллистический транспорт горячих неравновесных носителей заряда к контактам прибора (рис. 2). Указанная ситуация схожа с облучением лицевой стороны [13], так как в обоих случаях значительная доля неравновесных носителей заряда генерируется в области сильного электрического поля. Имитационный эксперимент в этом случае максимально затруднен, так как требует подбора не только интенсивности и длительности лазерного излучения, но и длины волны.

Различная динамика разогрева и релаксации энергии неравновесных носителей заряда в треке заряженной частицы и при воздействии лазерного импульса длительностью 10 фс с длинами волн 870 и 670 нм обусловливают расхождения в длительности переходного ионизационного процесса (рис. 3). Передний фронт импульса тока при воздействии заряженных частиц корректнее имитируется лазером с длиной волны 670 нм. В обоих случаях горячие носители заряда покидают рабочую область диода быстрее термализованных носителей заряда, генерируемых лазером с длиной волны 870 нм. Поэтому длительность переходного ионизационного процесса меньше, а его максимальная амплитуда
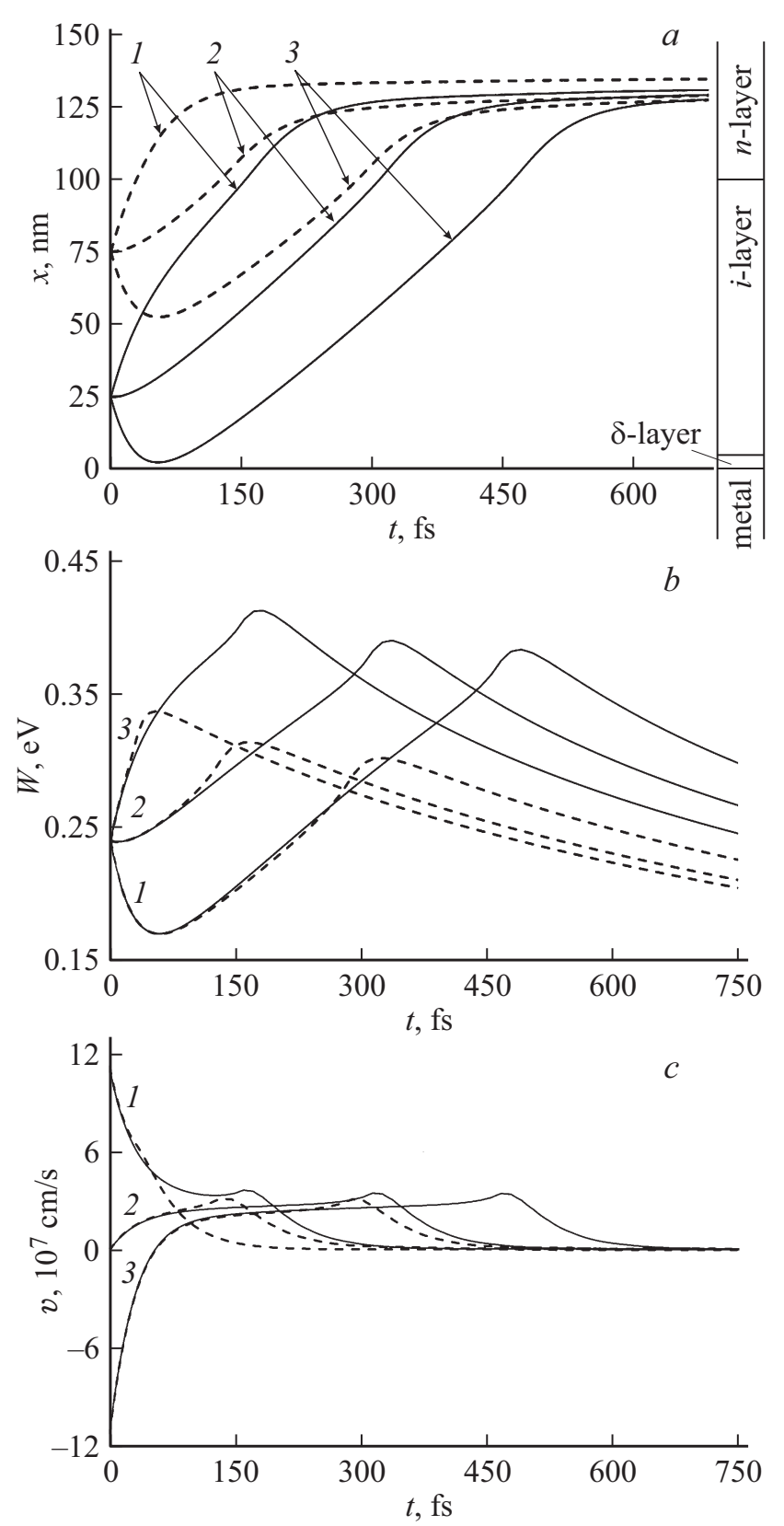

Рис. 2. Зависимости от времени координаты $x$ радиационногенерированного электрона $(a)$, средней энергии $W$ неравновесных радиационно-генерированных электронов $(b)$, средней скорости $v$ неравновесных радиационно-генерированных электронов (c). Начальная энергия электронов 0.24 эВ, начальная координата по отношению к металлическому контакту 25 (сплошная линия) и 75 нм (штриховая), угол между векторами начальной скорости и напряженности электрического поля $180(1), 90(2), 0^{\circ}(3)$.

выше при воздействии заряженных частиц и лазерного импульса с длиной волны $670 \mathrm{Hм}$, чем при воздействии лазерного импульса с длиной волны 870 нм. Запаздывающая относительно воздействующего импульса излучения составляющая ионизационного тока формируется термализованными носителями заряда. Поэтому задний фронт 


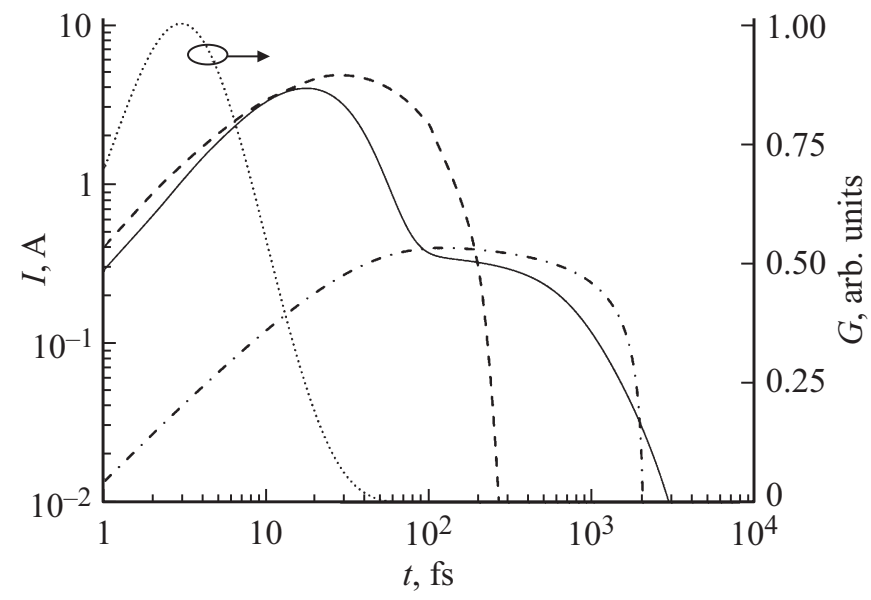

Рис. 3. Переходный ионизационный процесс в $i$-слое диода Мотта при воздействии ионов As c энергией $200 \mathrm{MэB}$ (сплошная линия), лазерного импульса длительностью 10 фс с длиной волны 870 нм (штрихпунктирная), лазерного импульса длительностью 10 фс с длиной волны 670 нм (штриховая). Точечная линия - форма лазерного импульса, вспомогательная шкала - нормированный коэффициент генерации $(G)$ неравновесных носителей в треке заряженной частицы или лазерном импульсе.

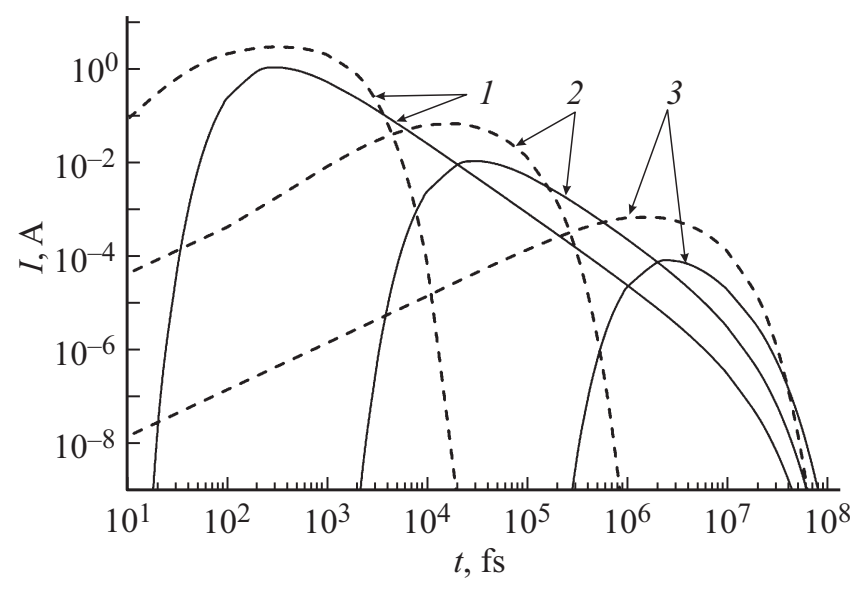

Рис. 4. Переходный ионизационный процесс в $n$-слое диода Мотта: сплошная линия - при воздействии ионов As c энергией $200 \mathrm{MэB}$, трек ионов проходит перпендикулярно оси структуры на расстоянии 0.2 (1), 2 (2), 20 мкм (3) от металлического контакта; штриховая линия - при воздействии лазерного импульса с длиной волны 870 нм и длительностью $0.5(1), 50$ (2), 5000 пс (3).

импульса тока корректнее описывается в случае лазера с длиной волны 870 нм.

\section{2. Трек заряженной частицы перпендикулярен линиям тока в $n$-области}

При попадании тяжелой заряженной частицы в область $n$-слоя подложки (наиболее вероятная ситуация) движение неравновесных носителей заряда будет носить преимущественно диффузионный характер с релаксаци- ей энергии к равновесному состоянию. В этом случае действие пикосекундного импульса излучения с энергией фотонов, равной ширине запрещенной зоны, должно быть максимально адекватным.

Переходный ионизационный процесс в низкобарьерном диоде Мотта при прохождении тяжелой заряженной частицы в $n$-области перпендикулярно оси анод-катод представлен на рис. 4. Видно, что при попадании тяжелой заряженной частицы в $n$-слой подложки длительность переходного ионизационного процесса и максимальная амплитуда фототока $I$ определяются характерным расстоянием между треком тяжелой заряженной частицы и металлическим контактом диода - чем больше расстояние от поверхности, тем сильнее „расплывается“ область термализованных неравновесных носителей, тем больше длительность импульса и ниже его амплитуда. Полученный результат находится в соответствии с аналитической моделью диффузионной ионизационной реакции полупроводниковых элементов при воздействии тяжелых заряженных частиц [22].

Из рис. 4 видно, что переходный ионизационный процесс при воздействии лазерного импульса всегда короче процесса при аналогичном воздействии заряженной частицы в n-области. Это обусловлено тем, что облучение лазером проводится с лицевой стороны, т.е. часть носителей заряда сразу попадает в область сильного электрического поля $i$-слоя, минуя диффузионное движение в области подложки. Длительность импульсов оптического излучения варьировалась в пределах 0.5-5000 пс, что следовало из условия совпадения времен максимального ионизационного тока при воздействии тяжелых заряженных частиц и лазерных импульсов.

\section{5. Заключение}

Результаты проведенного моделирования показали, что при уменьшении времени пролета электронов до характерных времен прохождения тяжелых заряженных частиц через рабочую область полупроводниковых структур существенную роль начинают играть физические процессы, связанные с разогревом носителей заряда ионизирующим излучением. При попадании заряженной частицы в область сильного поля диода Мотта $(i$-слой $)$ возможна корректная имитация лазерным импульсом либо переднего фронта, либо заднего фронта переходного ионизационного процесса, что обусловлено различием динамики разогрева и релаксации энергии неравновесных носителей заряда в треке заряженной частицы при воздействии фемтосекундного титан-сапфирового лазерного импульса с перестраиваемой длиной волны.

В заключение еще раз подчеркнем, что рассмотрение влияния разогрева электронно-дырочного газа излучением и различий пространственно-временны́х распределений неравновесных носителей заряда имеет смысл толь- 
ко для высокочастотных субмикрометровых полупроводниковых приборов. В противном случае характеристики одиночных радиационных эффектов будут определяться исключительно локальностью энерговыделения. При этом длительность лазерного импульса должна быть меньше характерных времен пролета носителями заряда рабочей области и перезарядки внутренних емкостей полупроводниковой структуры. Это накладывает особые условия на состав имитационных установок, а также измерительную оснастку и регистрирующую аппаратуру при проведении испытаний субмикрометровых сверхвысокочастотных устройств на воздействие тяжелых заряженных частиц космического пространства и излучений, их имитирующих.

\section{Финансирование работы}

Работа выполнена в рамках базовой части государственного задания, проект 0729-2020-0057.

\section{Конфликт интересов}

Авторы заявляют, что у них нет конфликта интересов.

\section{Список литературы}

[1] А.А. Гриценко. REDS: Телекоммуникационные устройства и системы, 7 (1), 9 (2017).

[2] В.И. Шашкин, А.В. Мурель, Ю.Н. Дроздов, В.М. Данильцев, О.И. Хрыкин. Микроэлектроника, 26 (1), 57 (1997).

[3] В.Р. Закамов, В.И. Шашкин. РЭ, 56 (8), 1009 (2011).

[4] C.H.P. Lorenz, S. Hemour, Ke Wu. IEEE Trans. Microware Theory and Techniques, 64 (7), 2146 (2016).

[5] В.И. Шашкин, В.Л. Вакс, В.М. Данильцев, А.В. Масловский, А.В. Мурель, С.Д. Никифоров, О.И. Хрыкин, Ю.И. Чеченин. Изв. вузов. Радиофизика, 48 (6), 1 (2005).

[6] V.I. Shashkin, Yu.A. Drjagin, V.R. Zakamov, S.V. Krilov, L.M. Kukin, A.V. Murel, Yu.I. Chechenin. Int. J. Infrared Waves, 28, 945 (2007).

[7] В.И. Шашкин, Ю.И. Белов, П.В. Волков, А.В. Горюнов, В.Р. Закамов, И.А. Илларионов. Письма ЖТФ, 39 (12), 44 (2013).

[8] П.В. Волков, Н.В. Востоков, А.В. Горюнов, Л.М. Кукин, В.В. Паршин, Е.А. Серов, В.И. Шашкин. Письма ЖТФ, 45 (5), 56 (2019).

[9] S.A. Korolyov, A.P. Shilov, A.V. Goryunov, V.I. Shashkin. IEEE Sens. Lett., 4 (5), 3500404 (2020).

[10] B. Kapilevich, V. Shashkin, B. Litvak, G. Yemini, A. Etinger, D. Hardon, Y. Pinhasi. IEEE Microware and Wireless Components Lett., 26 (8), 637 (2016).

[11] А.И. Чумаков, А.А. Печенкин, А.Н. Егоров, О.Б. Маврицкий, С.В. Баранов, А.Л. Васильев, А.В. Яненко. Микроэлектроника, 37 (1), 45 (2008).

[12] А.Н. Егоров, В.А. Телец, А.И. Чумаков, О.Б. Маврицкий, А.А. Печенкин, А.В. Яненко, Д.О. Кольцов. Электроника, 17 (5), 60 (2012).

[13] А.С. Пузанов, В.В. Бибикова, И.Ю. Забавичев, Е.С. Оболенская, Е.А. Тарасова, Н.В. Востоков, С.В. Оболенский. Письма ЖТФ, 47 (6), 51 (2021).
[14] S.V. Obolensky, A.V. Murel, N.V. Vostokov, V.I. Shashkin. IEEE Trans. Electron Dev., 58 (8), 2507 (2011).

[15] С. Зи. Физика полупроводниковых приборов (М., Мир, 1984) кн. 2, с. 447.

[16] Н.В. Демарина, С.В. Оболенский. ЖТФ, 72 (1), 66 (2002).

[17] А.С. Пузанов, С.В. Оболенский, В.А. Козлов. ФТП, 52 (11), 1295 (2018).

[18] А.С. Пузанов, С.В. Оболенский, В.А. Козлов. ФТП, 54 (8), 791 (2020).

[19] И.Ю. Забавичев, К.А. Насеткин, Е.С. Оболенская, А.С. Пузанов, Е.А. Тарасова. Науч.-техн. вестн. Поволжья, 11 (12), 209 (2020).

[20] Ф.Ф. Комаров. Успехи физ. наук, 187 (5), 465 (2017).

[21] Электронный pecypc http://www.srim.org

[22] А.В. Согоян, А.И. Чумаков. Микроэлектроника, 46 (4), 305 (2017).

Редактор Л.В. Шаронова

\section{Modeling the response of a microwave low-barrier uncooled Mott diode to the action of heavy ions of outer space and femtosecond laser pulses}

A.S. Puzanov 1,2, V.V. Bibikova ${ }^{\mathbf{1 , 2}}$, I.Yu. Zabavichev ${ }^{\mathbf{1 , 2}}$, E.S. Obolenskaya ${ }^{1}$, A.A. Potekhin ${ }^{2}$, E.A. Tarasova ${ }^{1}$, N.V. Vostokov ${ }^{3}$, V.A. Kozlov ${ }^{3}$, S.V. Obolensky ${ }^{1,2}$

${ }^{1}$ Lobachevski University of Nizhny Novgorod, 603950 Nizhny Novgorod, Russia

${ }^{2}$ Branch of Russian Federal Nuclear Center

All-Russian Research Institute of Experimental Physics „Sedakov Scientific Research Institute of Measurement Systems", 603950 Nizhny Novgorod, Russia ${ }^{3}$ Institute for Physics of Microstructures, Russian Academy of Sciences, 603950 Nizhny Novgorod, Russia

Abstract A theoretical analysis of degradation of a currentvoltage characteristic and transient ionization processes occurring in a low-barrier uncooled GaAs Mott diode under the action of heavy ions of outer space and laser pulses simulating them is carried out. The response of the diode to the action of an arsenic ion with energy of $200 \mathrm{MeV}$, corresponding to a linear energy transfer of $26 \mathrm{MeV} \cdot \mathrm{cm}^{2} / \mathrm{mg}$, is compared with the response to the action of femtosecond optical radiation pulses with a duration of $10 \mathrm{fs}$ with wavelengthes of 870 and $670 \mathrm{~nm}$. 